\title{
Experiments on Enhancing the Particle Charging Performance of an Electrostatic Precipitator
}

\author{
Chenghang Zheng, Dawei Duan, Qianyun Chang, Shaojun Liu, Zhengda Yang, Xintao Liu, \\ Weiguo Weng, Xiang Gao*
}

\author{
State Key Lab of Clean Energy Utilization, State Environmental Protection Engineering Center for Coal-Fired Air \\ Pollution Control, Zhejiang University, Hangzhou 310027, China
}

\begin{abstract}
Particle charging is an essential process for electrostatic precipitators (ESPs) in removing particles. A particle charge measurement system, which can adjust the flue gas temperature, was designed to study the effects of the flue gas parameters (viz., temperature and humidity), particle composition, and discharge electrodes on particle charging. The particle charge increased with the temperature when the applied electric field strength was constant. For particles with a diameter of $0.73 \mu \mathrm{m}$, the average charge increased by $30 \%$ (from $140 e$ to $183 e$ ) when the temperature increased from $300 \mathrm{~K}$ to $363 \mathrm{~K}$. Furthermore, with a constant electric field strength of $-4.2 \mathrm{kV} \mathrm{cm}^{-1}$, the average charge increased by $98 \%$ when the relative dielectric constant increased from 4.5 to 11.8 . Increased relative humidity significantly accelerated particle charging. For particles $>0.1 \mu \mathrm{m}$, the average charge increased by more than $50 \%$ when the relative humidity increased from $30 \%$ to $80 \%$. Optimizing the discharge electrode also enhanced charging. After the wire electrode $(d=1 \mathrm{~mm})$ was replaced by a ribbon electrode, particle charging increased by more than $75 \%$ for $0.7 \mu \mathrm{m}$ particles at $-4.2 \mathrm{kV} \mathrm{cm}$.
\end{abstract}

Keywords: Particle charging; Temperature; Humidity; Discharge electrode; Relative dielectric constant.

\section{INTRODUCTION}

The global consumption of coal by the power sector is estimated to increase over the next two decades (ExxonMobil, 2017). In China, nearly $50 \%$ of coal is consumed in coalfired power plants (Wang et al., 2015). Many pollutants, such as $\mathrm{NO}_{\mathrm{x}}$ and $\mathrm{SO}_{\mathrm{x}}$, are generated during the coal combustion process (Hu et al., 2017; Yang et al., 2018b, c; Wang et al., 2019; Zheng et al., 2019). Among pollutants, particulate matter (PM) can result in potential visibility problems and adverse effects on human health (Crilley et al., 2014; Kim et al., 2015; Yang et al., 2017; Lin et al., 2018; Zheng et al., 2018; Li et al., 2019; Zhou et al., 2019). Therefore, developing technology to control PM emission is essential.

The electrostatic precipitator (ESP) is a well-known, highly efficient device for cleaning exhaust gases from industrial processes (Wang et al., 2015; Sun et al., 2018; Yang et al., 2018a). The overall mass-based collection efficiencies of ESPs can exceed 99\% (Xu et al., 2016a, b). However, a decrease in collection efficiency was observed for different kinds of particles with the reduction in particle

\footnotetext{
* Corresponding author.

Tel.: +86-571-87951335; Fax: +86-571-87951616

E-mail address: xgao1@zju.edu.cn
}

size to between 0.1-1 $\mu \mathrm{m}$ (Zhuang et al., 2000). One important reason for the decrease is the low charging efficiency of fine particles (Lawless, 1996). Studying the charging mechanism of particles is useful for enhancing the charging efficiency. Different numerical techniques, theoretical models, and experiments have been proposed and developed to elucidate the charging mechanism of particles.

Numerical techniques have been adopted by researchers to analyze particle charging to model unipolar chargers. The Monte Carlo simulation was developed to capture the charging characteristics of particles with complex shapes (Biskos et al., 2004). Apart from the Monte Carlo simulations of theoretical charging processes, numerical techniques were also developed to analyze the charging process in unipolar chargers. A 2D numerical model was developed to predict the charging process in real unipolar chargers with complex geometries, which contain the fully coupled calculation of the flow, electric potential, and ion concentration fields and the charging dynamics of particles (Chien et al., 2011; Chien and Tsai, 2013). In the aspect of theoretical models, a nonspherical particle charging model for particles of all sizes and a charge distribution model for particles sized $0.01-10 \mu \mathrm{m}$ were developed in recent years (Gopalakrishnan et al., 2013; Domat et al., 2014). Many measurements of electric charges were developed to confirm the validity of the field charging model. Frank et al. (2004) measured the electric 
charge on droplet particles sized $0.1-20 \mu \mathrm{m}$ by using three different methods. The average charges were fairly consistent with the prediction of the combined charging model of Lawless (1996). Long and Yao (2010) analyzed different kinds of charging models in the continuum regime and compared their data with the experimental data (Hewitt, 1957), which indicated that the model established by Lawless should be the first choice for modeling the particle charging dynamics in ESPs. The effect of the dielectric constant of materials on the unipolar diffusion charging of nanoparticles was also investigated (Shin et al., 2009). Xu et al. (2009) investigated the effect of power supply with different frequencies and different particle flow rates on particle charging. Park et al. (2011) used multichannel chargers to demonstrate that increasing ion concentration is an important factor in increasing the average charge of the particles. Another new charger (Alonso and Huang, 2015) was also designed to enhance the nanoparticle charge.

Although many experiments were conducted, most of them mainly focused on the effects of the charge devices, particle sizes, and ion concentrations on the particle. How to adjust the actual operating conditions of the ESP and the main particle component to enhance the particle charge is unclear (Zheng et al., 2016). In this research, a particle charge measurement system was designed to study the effects of particle properties, flue gas parameters, and discharge electrodes on particle charge. The temperature varied from $293 \mathrm{~K}$ to $383 \mathrm{~K}$, and the range of relative humidity was 0 $100 \%$, which were aimed at how to improve the efficiency of ESP under real operating conditions. The effects of different discharge electrodes, including ribbon electrode, sawtooth electrode, screw electrode, and two wire electrodes $(\mathrm{d}=1,3 \mathrm{~mm})$, on particle charge were compared. Six types of particles, namely, power plant fly ash (Ash A), coal pyrolysis furnace fly ash (Ash B), glass bead (Particle C), silica (Particle D), aluminum oxide (Particle E), and calcium oxide (Particle F), were investigated. This research mainly aimed to study how the main particle component, flue gas parameters, and discharge electrodes influence the charging mechanism of particles and to obtain the method of enhancing the particle charge.

\section{EXPERIMENTAL SETUP AND METHODS}

A schematic of the experimental system is shown in Fig. 1. The system consisted of five parts, namely, a gascontrolled system, particle feeders, a particle charging device, a high-voltage power supply, and a particle charge measurement system.

The gas-controlled system consisted of a fan, a buffer vessel, an electric heater, and a rotameter. The main stream of simulated flue gas was produced by a draught fan from the air with a maximum flow rate of $70 \mathrm{~L} \mathrm{~min}^{-1}$ during the experiments. The buffer vessel was a cylindrical metal barrel, with a diameter of $20 \mathrm{~cm}$ and a height of $40 \mathrm{~cm}$, connected to the middle of the pipeline linked to the feeder and the charging system. This configuration prevented excess particles from depositing in and blocking the pipes and aimed to adjust the flow rate. The relative humidity of the gas, which ranged from $0 \%$ to $100 \%$, was measured by an electronic hygrometer (CX309; Anseny, Ltd., China). The gas temperature was controlled in the range of $293 \mathrm{~K}$ to $383 \mathrm{~K}$ by an electric heater. The temperature of these experiments was generally $313 \mathrm{~K}$, apart from the experiments aimed at exploring particle charging characteristics at different temperatures. All pipes were covered with thermal insulation material to reduce undesired heat loss. In addition, the designed pipelines in were as straight and short as possible to reduce the mass loss. Then, the gas entered the charging system. The charging time varied in the range of $0.06-0.1 \mathrm{~s}$ by changing the gas flow rate using the rotameter. Afterward, the particle charge and concentration were measured at the outlet of the particle charging system. The measurement was taken when each experiment was adjusted to a stable condition as the experiment required. The time of each experiment was very short, usually within 2 minutes.

Six types of particles, namely, power plant fly ash (Ash A), coal pyrolysis furnace fly ash (Ash B), glass bead (Particle C), silica (Particle D), aluminum oxide (Particle E), and calcium oxide (Particle F), were used to study the charging characteristic of different particles. The experimental particle mass concentration and the number concentration were approximately $120 \mathrm{mg} \mathrm{m}^{-3}$ and 190,000 $\mathrm{\#} \mathrm{cm}^{-3}$, respectively. The experimental particles of these experiments were generally power plant fly ash, apart from the experiments aimed at exploring effect of the main particle component on particle charging. The particles were injected into the simulated flue gas by an electromagnetic vibrating feeder, which was self-designed and consisted of four springs and an electromagnet system. When the electromagnet was magnetized, the springs would be extruded and the base of the spring moved downward. The particles moved forward with the vibration of the base, then entered the inlet of the pipes through the connecting tube. The feeding rate could be adjusted in accordance with the vibration frequency of the vibration controller, of which the vibration frequency range was $0-100 \mathrm{~Hz}$. The particle feeder was replaced by an aerosol generator (Condensation Monodisperse Aerosol Generator Model 3475; TSI Inc., USA) to study the particle charging characteristics at different temperatures. It can produce polydisperse aerosol particles with an average particle size of $0.1-8 \mu \mathrm{m}$, which are almost electrically neutral. The material it generated was bis(2-ethylhexyl) sebacate (DEHS) aerosol particles, which were generated by the DEHS vapor condensing on the sodium chloride crystal nucleus. In this research, the total mass and number concentration of the generated aerosol particles was approximately $120 \mathrm{mg} \mathrm{m}^{-3}$ and $233,843 \mathrm{\#} \mathrm{cm}^{-3}$, respectively, which were controlled by adjusting the nitrogen pressure, saturator flow valve, temperature, and reheater temperature.

The particle charging device was a wire-plate discharge configuration with a negative direct current power supply (TRC2020; Teslaman Electronics Co., Ltd., China). The wire-plate negative corona discharge device, which was made of plexiglass $(600 \mathrm{~mm}$ long, $200 \mathrm{~mm}$ wide, and $100 \mathrm{~mm}$ high), consisted of a wire discharge electrode and 


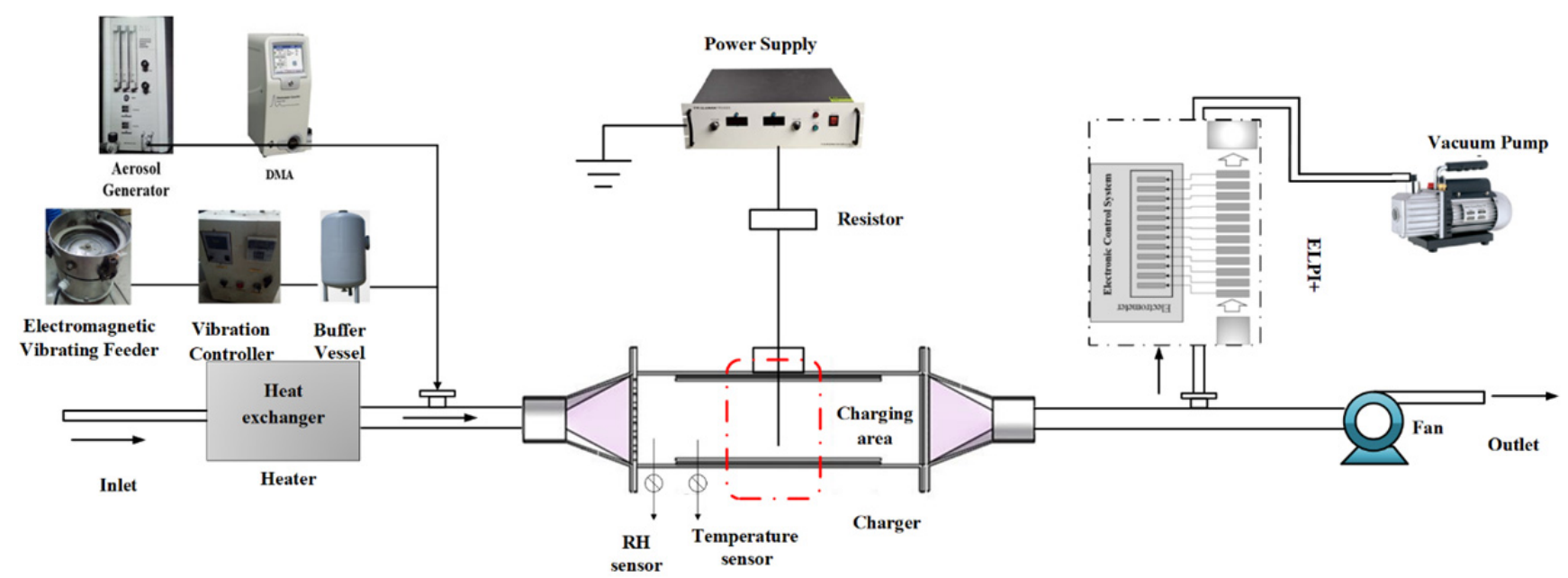

(a) The particle charge measurement system.

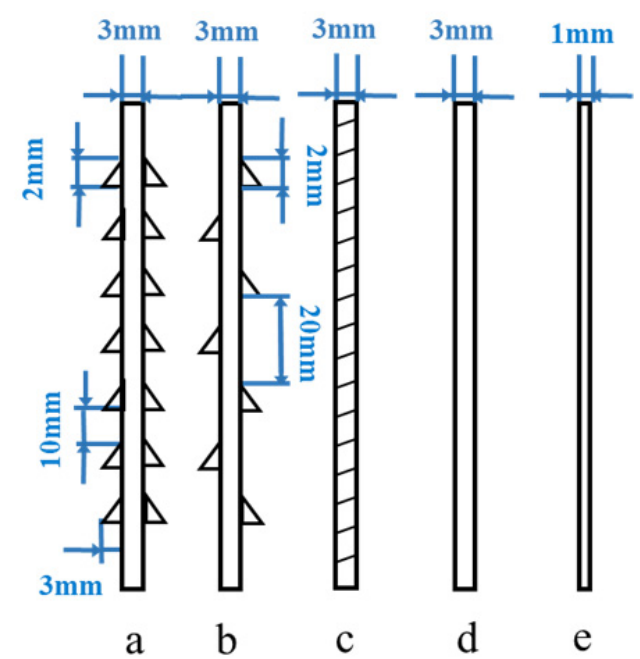

a: ribbon electrode; b: sawtooth electrode; c: screw electrode; $\mathrm{d}$ : wire electrode $(3 \mathrm{~mm})$; e: wire electrode (1 mm).

(b) Geometry of discharge electrodes 2

Fig. 1. Schematic of the experimental system.

two grounded plates. The plates were cleaned after finishing several experiments to avoid the influence of precipitated aerosol. Ribbon electrode, sawtooth electrode, screw electrode, and two wire electrodes with diameters of 1 and $3 \mathrm{~mm}$ were used as the discharge electrodes (as shown in Fig. 1). The ribbon electrode was generally used as the discharge electrode, apart from the experiments aimed at exploring the effect of electrodes on particle charge. The discharge electrodes were $200 \mathrm{~mm}$ long, and the discharge gap was $50 \mathrm{~mm}$. The length of the corona discharge region was $60 \mathrm{~mm}$. The charging time was generally $0.1 \mathrm{~s}$, while the charging time of the experiments aimed at effect of dielectric constant was $0.06 \mathrm{~s}$. The charging time set can minimize the deposition of particles while ensuring sufficient charging time (Long and Yao, 2010). The negative high voltage generated by the negative power supply with a range of $0-30 \mathrm{kV}$ was applied to the discharge electrode.

The particle measurement system consisted of an electrostatic low-pressure impactor (ELPI+; Dekati, Ltd.,
Finland), a vacuum pump (SV25B; Ernst Leybold, Ltd., Germany), and a sampling probe. The inside of the sampling probe was technically coated to prevent electrostatic adsorption, which can minimize the loss of small particles. Using the vacuum pump, the flue gas was sampled through the sampling probe at a flow rate of $10 \mathrm{~L} \mathrm{~min}^{-1}$. The particle charge and number concentration of particles of different sizes were obtained by the ELPI+. The measured size range of the particles was $0.006-10 \mu \mathrm{m}$, and these particles were classified into 14 stages. The particle number concentration of each stage was obtained by detecting the signal of the induced current.

The particle number concentration was calculated using the fractional current resulting from the continuous deposition of charged particles on each aluminum/polycarbonate foil. As expressed in Eq. (1), the ELPI+ will automatically convert the measured current into the fractional concentration of the particles:

$I=P n e Q N$ 
where $I$ is the fractional current, $N$ is the fractional number concentration of particles, $P$ is the fractional efficiency of particle charging, $n$ is the number of elementary charges carried by the particle, $e$ is the elementary charge $(1.602 \times$ $\left.10^{-19} \mathrm{C}\right)$, and $Q$ is the sampling flow rate $\left(10 \mathrm{~L} \mathrm{~min}^{-1}\right)$. The power plant fly ash size distribution measured by the ELPI+ is shown in Fig. 2.

After closing the charger of the ELPI+, the charge of a particle was calculated using the signal of the fractional induced current of the ELPI+. For each experiment, $n$ is calculated using Eq. (2):

$n_{1}=\frac{I_{1}}{Q_{1} \times n \times e}$

where $n_{1}$ is the number of elementary charges carried by a particle, $I_{1}$ is the signal of the fractional induced current of the ELPI+ (A), $Q_{1}$ is the sampling flow rate $\left(\mathrm{cm}^{3} \mathrm{~s}^{-1}\right), N$ is the particle number concentration $\left(\mathrm{cm}^{-3}\right)$, and $e$ is the elementary charge $\left(1.602 \times 10^{-19} \mathrm{C}\right)$.

\section{RESULTS AND DISCUSSION}

\section{Particle Charging Characteristics at Different \\ Temperatures}

Fig. 3 shows the effect of temperature on particle charge at $-4.4 \mathrm{kV} \mathrm{cm}^{-1}$. The particle charge increased with increasing temperature and particle size. For the particles $0.73 \mu \mathrm{m}$ in size, the average particle charge was increased by $30 \%$ from $140 e$ to $183 e$ when the temperature increased from $300 \mathrm{~K}$ to $363 \mathrm{~K}$. Particle charge increased with increasing temperature (Fig. 4). With high applied electric field strength, the enhancement of particle charge with rising temperature was rapid. When the average applied electric field strength was $-6.0 \mathrm{kV} \mathrm{cm}^{-1}$, the particle charge increased

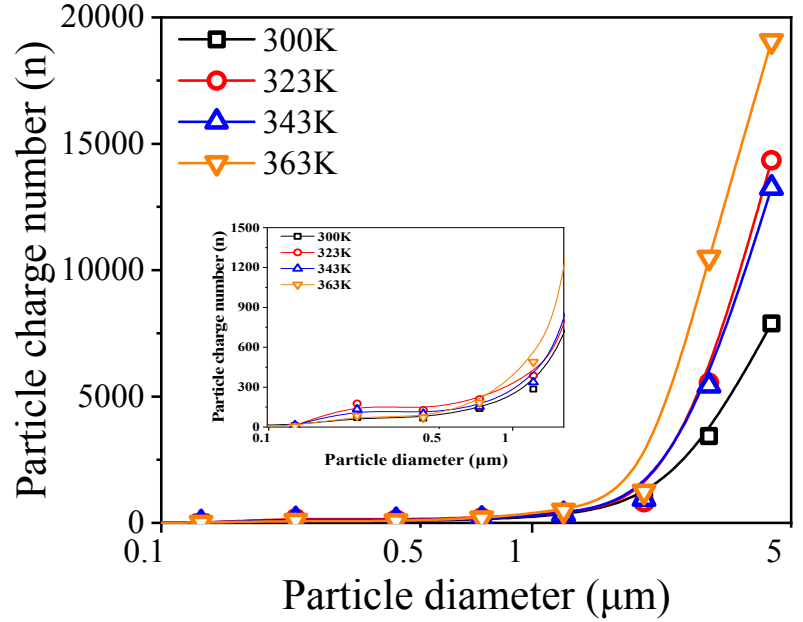

Fig. 3. Effect of temperature on particle.

from $1.8 \times 10^{4} e$ to $4.3 \times 10^{4} e$, with the temperature increasing from $300 \mathrm{~K}$ to $363 \mathrm{~K}$. By contrast, when the average applied electric field strength was $-6.4 \mathrm{kV} \mathrm{cm}^{-1}$, the particle charge increased from $1.8 \times 10^{4} e$ to $6.4 \times 10^{4} e$, with the temperature increasing from $300 \mathrm{~K}$ to $363 \mathrm{~K}$; the increment was more than that at the average applied electric field strength of $-6.0 \mathrm{kV} \mathrm{cm}^{-1}$. High temperature led to an increase in the mean free path of the surrounding gas molecules. A larger mean free path leads to more energy gained by an electron when it is accelerated in the applied electric field before colliding with a background molecule. The electron energy and probability of the gas molecule to be ionized increased with increasing mean free path (Hamou et al., 2013), such that the number of ions and the discharge current increased (as shown in Fig. 5). Therefore, the high temperature accelerated the particle charge at the same applied voltage.

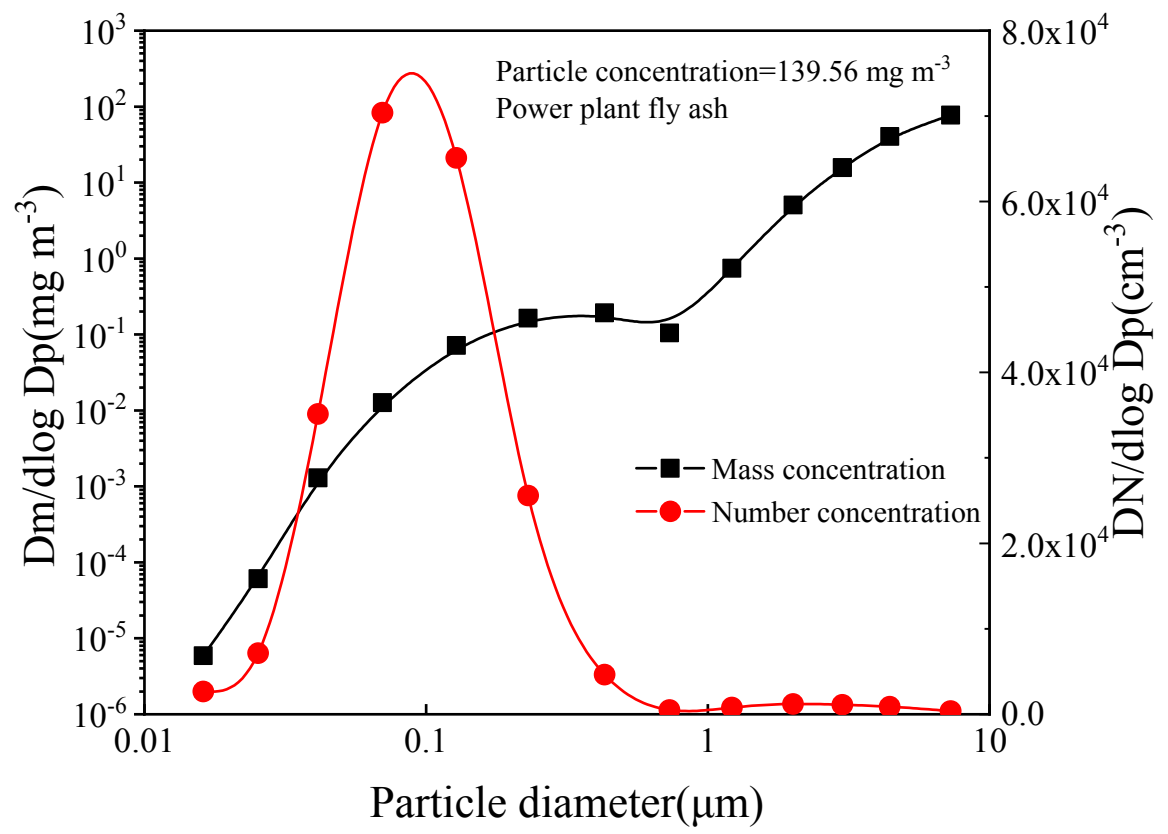

Fig. 2. Power plant fly ash size distribution. 


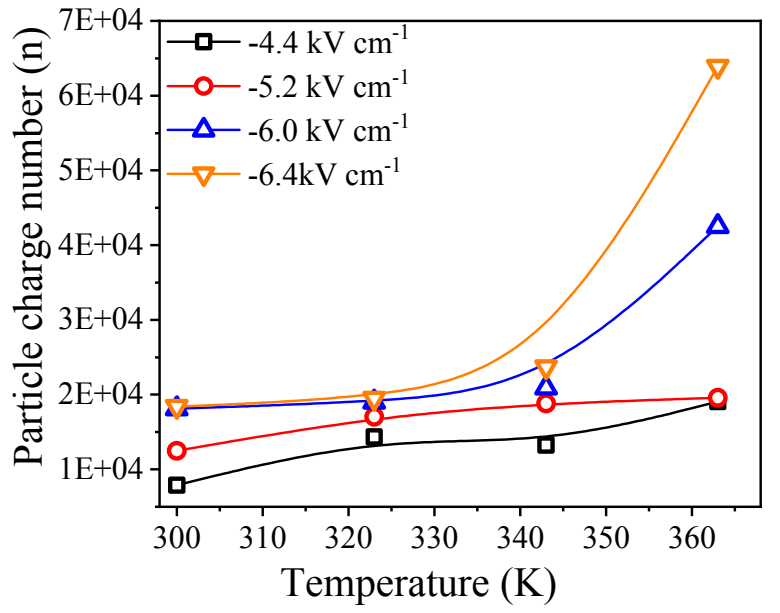

Fig. 4. Effect of temperature on particle charge at different applied voltages.

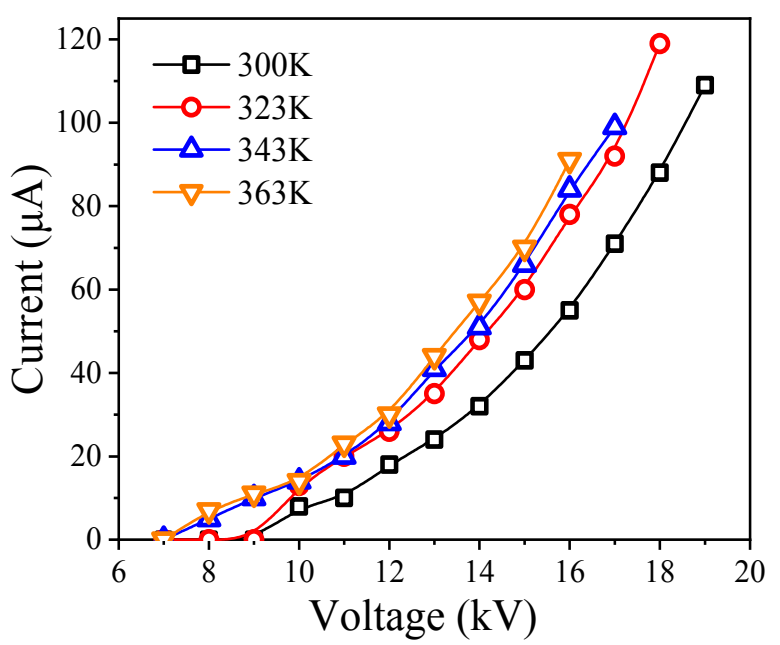

Fig. 5. I-V characteristics curve in different temperatures.

Fig. 6 shows the effect of temperature on particle charge at maximum applied voltages. For corona discharges above $323 \mathrm{~K}$, the particle charge decreased with increasing temperature. The maximum applied voltage (Ghaleb et al., 2008; Ghaleb and Belasri, 2012), electric field strength, and ion concentration in the corona discharge region decreased with increasing temperature. Hence, the movement of ions to the surface of the particles and the collision frequency decreased, thereby resulting in a corresponding decrease in the particle charge. For $293 \mathrm{~K}$ to $323 \mathrm{~K}$, the particle charge at $323 \mathrm{~K}$ was slightly higher than that at $293 \mathrm{~K}$ because the decrease in the maximum operating voltage was small. However, the accelerating effect of temperature on corona discharge was obvious. Therefore, the discharge current at $323 \mathrm{~K}$ was slightly higher than that at $293 \mathrm{~K}$. The ion concentration also increased. For particles smaller than $0.5 \mu \mathrm{m}$, diffusion charging was stronger than field charging (Jaworek et al., 2007). With the increase of temperature, the diffusion charging will be much stronger. Therefore, the charge of particles less than $0.5 \mu \mathrm{m}$ at $323 \mathrm{~K}$ was higher than that at $293 \mathrm{~K}$.

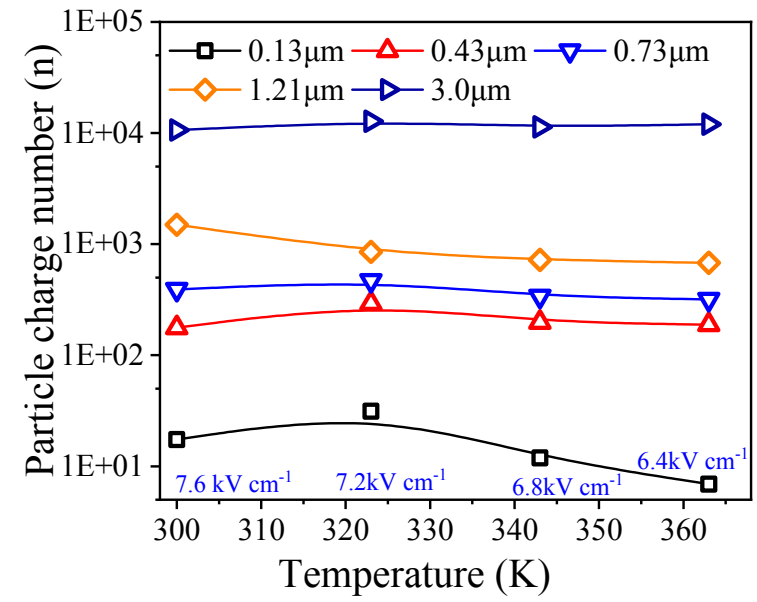

Fig. 6. Effect of temperature on particle charge at maximum applied voltages.

\section{Effect of the Main Particle Component on Particle Charging}

In this research, six types of particles, namely, power plant fly ash (Ash A), coal pyrolysis furnace fly ash (Ash B), glass bead (Particle C), silica (Particle D), aluminum oxide (Particle E), and calcium oxide (Particle F), were used to study the charging characteristic of different particles. Among these particles, Ashes A and B mainly consisted of silica, aluminum oxide, iron oxide, calcium oxide, and magnesium oxide. The main components of Particles D, E, and F were silica, aluminum oxide, and calcium oxide, respectively. The mass concentration of Ash/Particle A, B, C, D, E, and F was approximately 196, 91, 48, 149, 394, and $139 \mathrm{mg} \mathrm{cm}^{-3}$, respectively. The number concentration of Ash/Particle A, B, C, D, E, and F was approximately 182,489, 215,488, $208,578,155,549,210,959$, and $233,843 \mathrm{\#} \mathrm{cm}^{-3}$, respectively. During the experiment the particle mass and number concentration varied slightly around the set value. The particle charging characteristics of different main components under the conditions of $0.1 \mathrm{~s}$ charging time and $30 \%$ relative humidity are shown in Fig. 7. The particle charge under the same applied voltage was ranked in the order of $\mathrm{F}>\mathrm{E}>\mathrm{A}>\mathrm{B}>\mathrm{D}>\mathrm{C}$. As indicated by other researchers (Chełkowski, 1980), the relative dielectric constant of Particles C, D, E, and F are 4.3-5, 4.5, 9, and 11.8, respectively. In addition, X-ray fluorescence is used to detect the elemental compositions of Ashes A and B. For Ashes A and B, the relative dielectric constant is calculated using Eq. (3) (Rao et al., 2000):

$\ln \varepsilon=\sum x_{i} \varepsilon_{i}$

where $x_{\mathrm{i}}$ is the component $i$ taking up the percentage of the particle, and $\varepsilon_{\mathrm{i}}$ is the relative dielectric constant of component $i$. The relative dielectric constant of all experimental ashes is shown in Table 1 . The polarization capability of the particle with high relative dielectric constant is much stronger. Then, many more ions collided with the particle. Thus, the particle charging was enhanced. The particle charge under different applied voltages was investigated for clarification. 


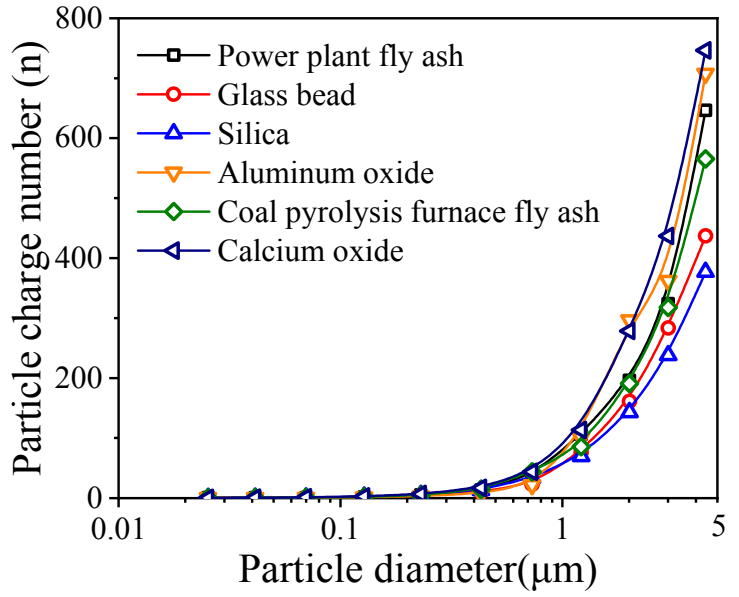

(a)

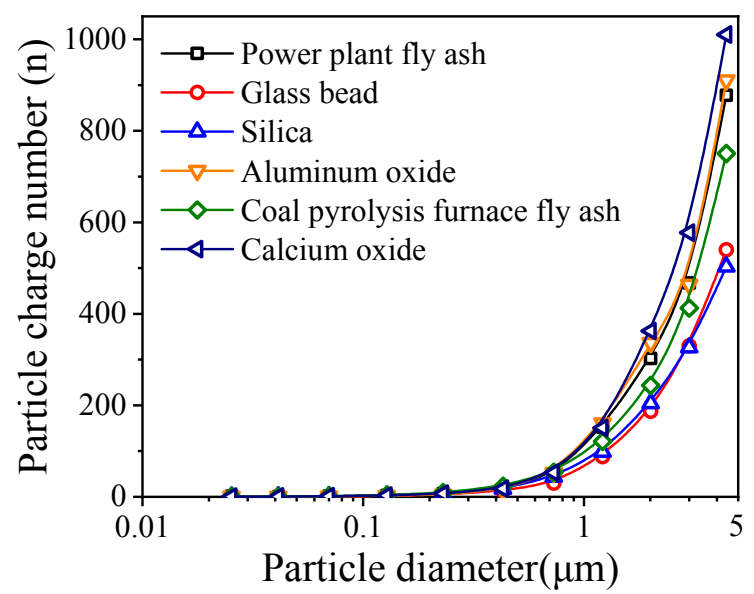

(b)

Fig. 7. Effect of main particle component on particle charge at different applied electric field strengths: (a) $-4.2 \mathrm{kV} \mathrm{cm}{ }^{-1}$; (b) $-5.0 \mathrm{kV} \mathrm{cm}^{-1}$.

Table 1. Relative dielectric constant of experimental ash.

\begin{tabular}{lllllll}
\hline Type & F & E & A & B & C & D \\
\hline Relative dielectric constant & 11.8 & 9 & 6.8 & 6.4 & $4.3-5$ & 4.5 \\
\hline
\end{tabular}

At the same applied voltage, particle charge increased with the dielectric constant. In addition, the particle charge at the same size was ranked in the order of $\mathrm{F}>\mathrm{E}>\mathrm{A}>\mathrm{B}$ $>\mathrm{D}>\mathrm{C}$, indicating that the difference in dielectric constant was the main reason for the evident change in charge for different types of particle. Therefore, the particle charge increased with the dielectric constant (Fig. 8). The particle charge was $377 e$ when the relative dielectric constant was 4.5 and increased to $746 e$ with increasing relative dielectric constant up to 11.8 at $-4.2 \mathrm{kV} \mathrm{cm}^{-1}$.

\section{Effect of the Humidity in Flue Gas on Particle Charging}

Fig. 9 reveals the effect of humidity on particle charge when the relative humidity is $10 \%, 30 \%, 60 \%$, and $80 \%$. The average applied electric field strengths are -4.2 and

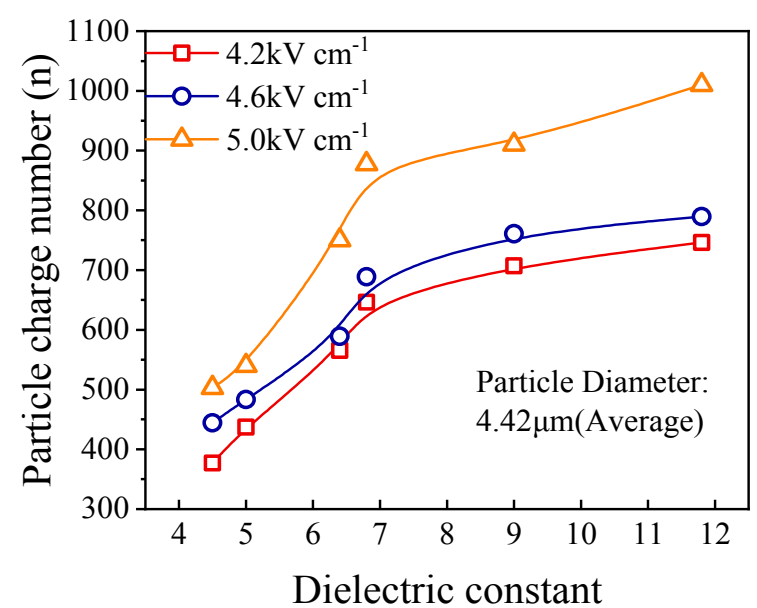

Fig. 8. Effect of dielectric constant on particle charge at different applied electric field strengths.
$-5.0 \mathrm{kV} \mathrm{cm}{ }^{-1}$, the charging time is $0.1 \mathrm{~s}$, and a ribbon electrode is used. The fly ash from a power plant was used as the experimental particle. For particles in the range of $0.1-10 \mu \mathrm{m}$, the particle charge increases with relative humidity under the same discharge voltage conditions. In addition, the enhancement of particle charge increased rapidly with the particle size (Fig. 9). Fig. 10 illustrates the effect of relative humidity on the charge of particle with diameters of $0.13,0.23,0.43 \mu \mathrm{m}$. For a particle, its charge increases with relative humidity. Increasing the relative humidity of the flue gas has a remarkable effect on the promotion of particle charge. For particles with sizes larger than $0.1 \mu \mathrm{m}$, the average charge was increased by more than $50 \%$ as the relative humidity increased from $30 \%$ to $80 \%$. On the one hand, the ionization coefficient increased with relative humidity in the air, thereby leading to drastic ionization process of neutral molecules in corona discharge. Thus, the ion density was high, the number of negative ions that move to the low electrical field strength area of ESP is higher, and the probability of collision with particle increases. Then the current increased (as shown in Fig. 11). Finally, a high relative humidity promotes particle charge. On the other hand, particle absorbed water vapor in the air in a stable high-humidity environment. The vapor condensed on the surface of the particle, thereby increasing the water content of the particle. The relative dielectric constant of water, which is 80 , is higher than that of the fly ash from the power plant (4-12). Therefore, compared with the completely dry particle, the polarization capability of the particle containing more water was very strong in the electric field, thereby allowing more electric field line to reach the surface of the particle. The collision between particles and ions was frequent. Thus, the particle charge was enhanced. 


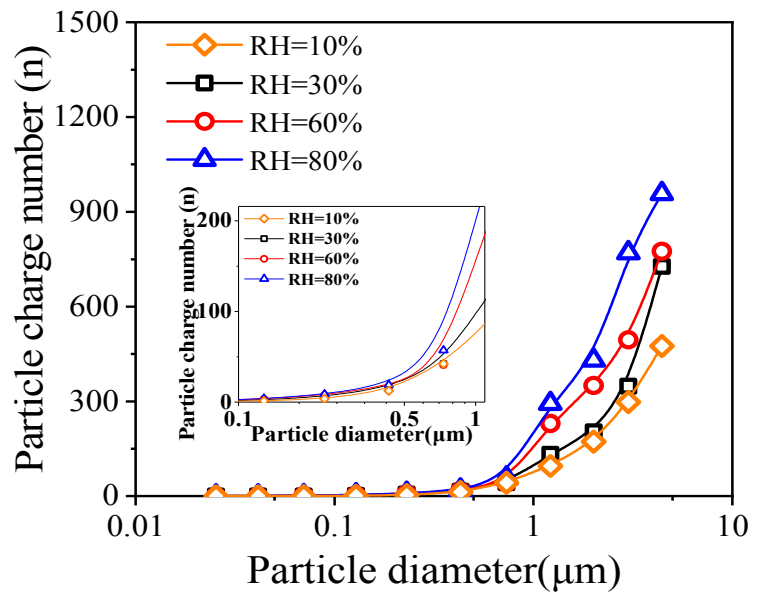

(a)

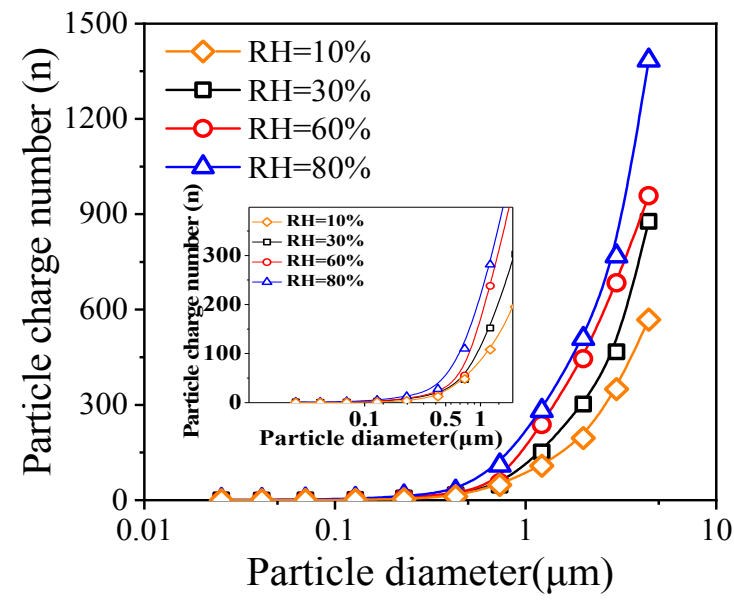

(b)

Fig. 9. Effect of relative humidity on particle charge at different applied electric field strengths: (a) $-4.2 \mathrm{kV} \mathrm{cm}{ }^{-1}$; (b) $-5.0 \mathrm{kV} \mathrm{cm}^{-1}$.

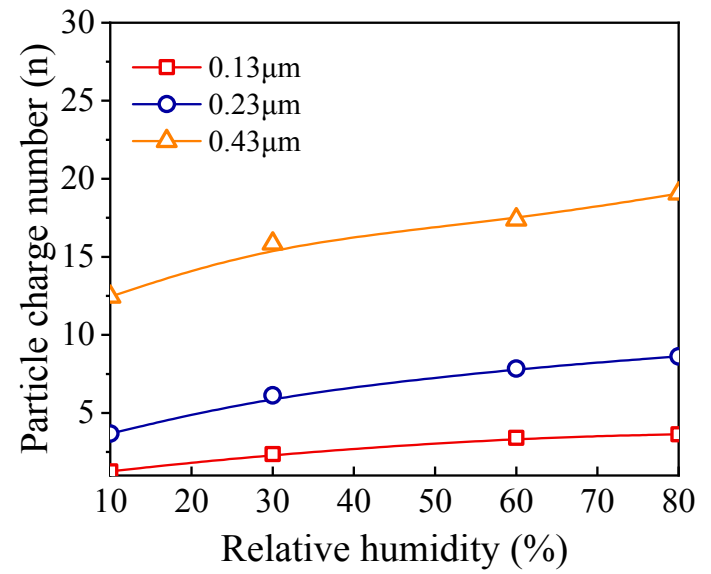

Fig. 10. Effect of relative humidity on particle charge with three different sizes.

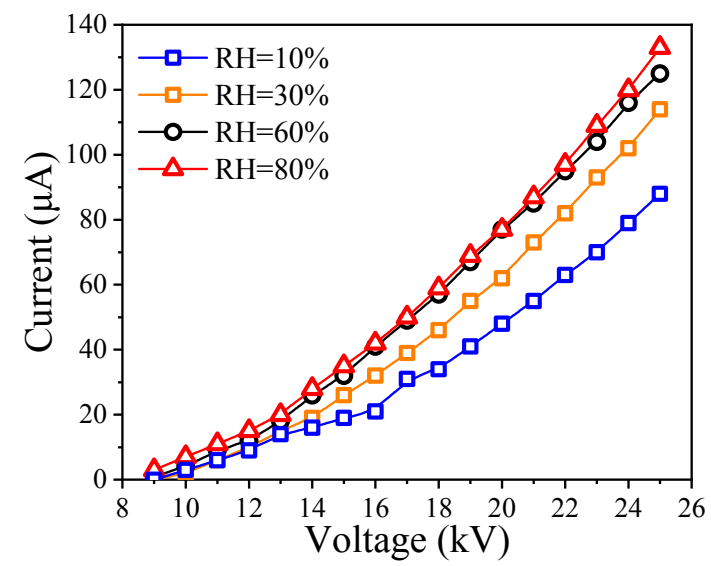

Fig. 11. I-V characteristics curve at different levels of humidity.

\section{Optimization of the Selection of a Discharge Electrode}

In this section, the effect of the electrode and current density on particle charge was studied. The corona current of different electrodes under the same applied voltage can be transformed into average current density by calculation. The current can be obtained by a current detecting device inside the power supply. The current density was calculated using Eq. (4) at the grounded plates:

$J=I / A$

where $J$ is the current density $\left(\mathrm{mA} \mathrm{m}^{-2}\right), I$ is the current $(\mathrm{mA})$, and $A$ is the area of each grounded plate $\left(\mathrm{m}^{2}\right)$.

Fig. 12 reveals the effect of electrodes on particle charge when the relative humidity is $80 \%$, the average applied electric field strength is $-4.2 \mathrm{kV} \mathrm{cm}$, and the charging time is $0.1 \mathrm{~s}$. In this research, five types of discharge electrodes, including ribbon, sawtooth, screw, and wire $(\mathrm{d}=1,3 \mathrm{~mm})$, were examined to determine the performance of particle charging. The maximum particle charge for different electrodes is ranked in the same order as the maximum current density is ranked for different electrodes (Fig. 12). At the same applied voltage, the particle charge of the ribbon electrode was larger than that of the other four electrodes. When the electrode changed from wire electrode $(\mathrm{d}=1 \mathrm{~mm})$ to ribbon electrode, the particle charge significantly rose to more than $75 \%$ for a particle size of $0.7 \mu \mathrm{m}$. At the same voltage, optimizing the electrode form greatly promoted the current density in the precipitator (as shown in Fig. 13) and then increased ion density and enhanced particle charge. The effect of current density on particle charging is shown in Fig. 14. For a particle with the same size, the increase of the particle charge was positively correlated with the increase of current density. The ion density increased with the current density. The frequency of the collision between particle and ion increased, thereby resulting in the promotion of particle charge.

\section{CONCLUSION}

In this study, a particle charge measurement system was designed to study the effects of particle composition and 


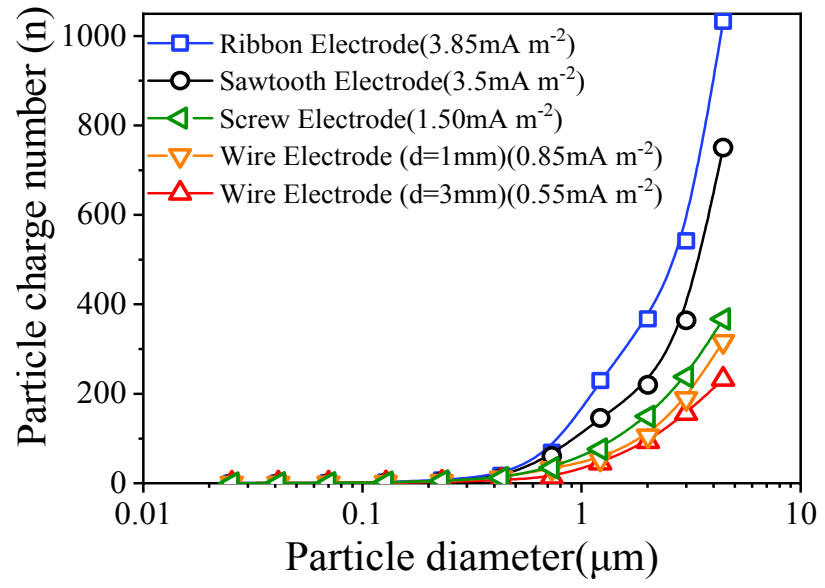

(a)

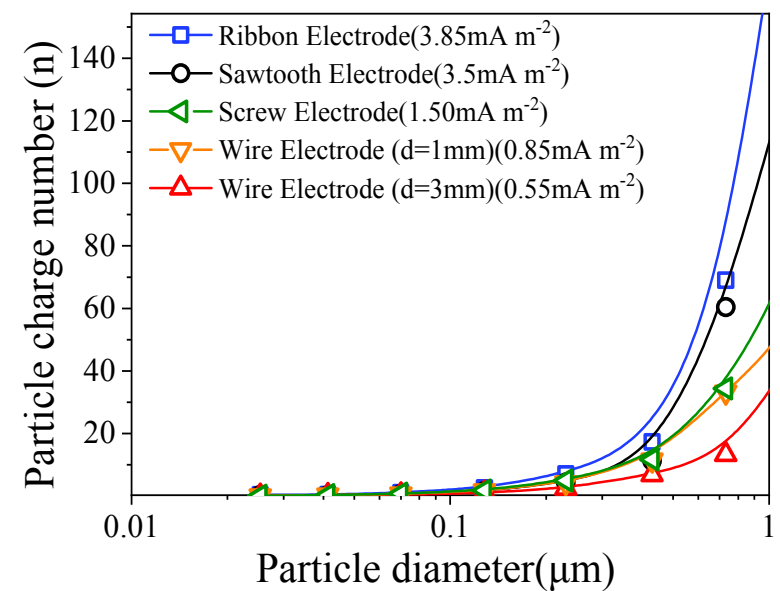

(b)

Fig. 12. Effect of electrodes on particle charge.

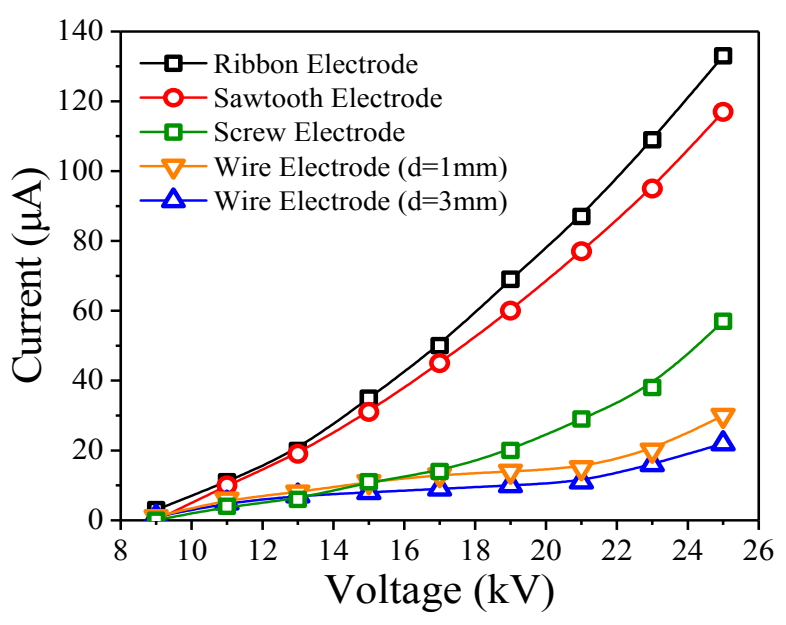

Fig. 13. I-V characteristics curve at different electrodes.

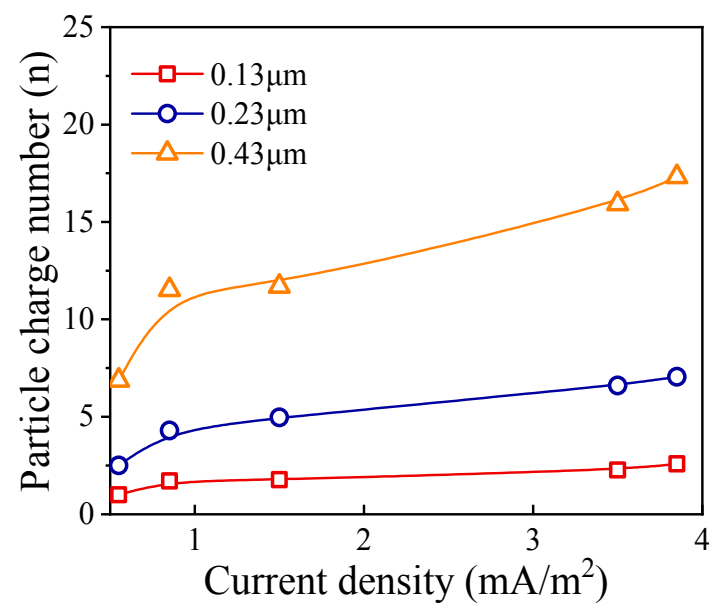

Fig. 14. Effect of current density on particle charge with different sizes.

flue gas parameters on particle charging. Based on the results, we present a series of methods for enhancing charging. The following conclusions can be drawn:
(1) Increasing the temperature while maintaining the same applied electric field strength can enhance particle charging. In addition, when the applied electric field strength is high, this enhancement is rapid.

(2) Charging can be significantly enhanced by optimizing the particle composition and thereby increasing the relative dielectric constant. The particle charge is $377 e$ when the relative dielectric constant is 4.5 ; when the constant increases to 11.8 at $-4.2 \mathrm{kV} \mathrm{cm}^{-1}$, however, the charge increases to $746 e$.

(3) High relative humidity promotes particle charging. The average charge of particles $>0.1 \mu \mathrm{m}$ increased by more than $50 \%$ when the relative humidity rose from $30 \%$ to $80 \%$.

(4) Particle charging is affected by the type of discharge electrode. The ribbon electrode, which discharges the largest current, is the optimal choice for particle charging, followed by the sawtooth, screw, and wire electrodes $(\mathrm{d}=1$ or $3 \mathrm{~mm})$. With an electric field strength of $4.2 \mathrm{kV} \mathrm{cm}^{-1}$, the ribbon electrode produces a charge of $70 e$ for $0.7 \mu \mathrm{m}$ particles, which is significantly higher than that of the other electrodes.

\section{ACKNOWLEDGMENTS}

This work was supported by the National Key Research and Development Program of China (No. 2017YFB063201) and National Natural Science Foundation of China (U1609212, 51621005).

\section{REFERENCES}

Alonso, M. and Huang, C.H. (2015). High-efficiency electrical charger for nanoparticles. J. Nanopart. Res. 17: 332 .

Biskos, G., Mastorakos, E. and Collings, N. (2004). Monte-Carlo simulation of unipolar diffusion charging for spherical and non-spherical particle. J. Aerosol Sci. 35: 707-730.

Chełkowski, A. (1980). Dielectric physics. Elsevier 
Science \& Technology.

Chien, C.L. and Tsai, C.J. (2013). Improvement of the nanoparticle charging efficiency of a single-wire corona unipolar charger by using radial sheath airflow: Numerical study. Aerosol Sci. Technol. 47: 417-426.

Chien, C.L., Tsai, C.J., Chen, H.L., Lin, G.Y. and Wu, J.S. (2011). Modeling and validation of nanoparticle charging efficiency of a single-wire corona unipolar charger. Aerosol Sci. Technol. 45: 1468-1479.

Crilley, L.R., Ayoko, G.A., Stelcer, E., Cohen, D.D., Mazaheri, M. and Morawska, L. (2014). Elemental composition of ambient fine particles in urban schools: Sources of children's exposure. Aerosol Air Qual. Res. 14: 1906-1916.

Domat, M., Kruis, F.E. and Fernandez-Diaz, J.M. (2014). Determination of the relevant charging parameters for the modeling of unipolar chargers. J. Aerosol Sci. 71: $16-28$.

ExxonMobil (2017) Outlook for Energy http://www.ind iaenvironmentportal.org.in/files/file/2017_Outlook_For Energy.pdf.

Frank, G.P., Cederfelt, S.I. and Martinsson, B.G. (2004). Characterisation of a unipolar charger for droplet aerosols of 0.1-2.0 $\mu \mathrm{m}$ in diameter J. Aerosol Sci. 35: $117-134$.

Ghaleb, F., Benstâali, W. and Belasri, A. (2008). Calculation of breakdown voltage in plasma display panels. Mater. Sci. Eng., C 28: 791-794.

Ghaleb, F. and Belasri, A. (2012). Numerical and theoretical calculation of breakdown voltage in the electrical discharge for rare gases. Radiat. Eff. Defects Solids 167: 377-383.

Gopalakrishnan, R., Thajudeen, T., Ouyang, H. and Hogan, C.J. (2013). The unipolar diffusion charging of arbitrary shaped aerosol particles. J. Aerosol Sci. 64: 60-80.

Hamou, N., Massinissa, A. and Youcef, Z. (2013). Modeling and simulation of the effect of pressure on the corona discharge for wire-plane configuration. IEEE Trans. Dielectr. Electr. Insul. 20: 1547-1553.

Hewitt, G.W. (1957). The charging of small particles for electrostatic precipitation. Trans. Am. Inst. Electr. Eng. Part I 76: 300-306.

Hu, W., Zhang, Y., Liu, S., Zheng, C., Gao, X., Nova, I. and Tronconi, E. (2017). Improvement in activity and alkali resistance of a novel $\mathrm{V}-\mathrm{Ce}\left(\mathrm{SO}_{4}\right)_{2} / \mathrm{Ti}$ catalyst for selective catalytic reduction of $\mathrm{NO}$ with $\mathrm{NH}_{3}$. Appl. Catal., B 206: 449-460.

Jaworek, A., Krupa, A. and Czech, T. (2007). Modern electrostatic devices and methods for exhaust gas cleaning: A brief review. J. Electrostat. 65: 133-155.

Kim, K.H., Kabir, E. and Kabir, S. (2015). A review on the human health impact of airborne particulate matter. Environ. Int. 74: 136-143.

Lawless, P.A. (1996). Particle charging bounds, symmetry relations, and an analytic charging rate model for the continuum regime. J. Aerosol Sci. 27: 191-215.

Li, X., Sun, W., Zhao, L. and Cai, J. (2019). Emission characterization of particulate matter in the ironmaking process. Environ. Technol. 40: 282-292.
Lin, N.H., Chang, M.B., Hwang, J., Kaneyasu, N. and Zhang, R. (2018). Overview of the special issue "Aerosol Source, Transport, Chemistry, and Emission Control" for the $10^{\text {th }}$ Asian Aerosol Conference 2017. Aerosol Air Qual. Res. 18: 1515-1518.

Long, Z. and Yao, Q. (2010). Evaluation of various particle charging models for simulating particle dynamics in electrostatic precipitators. J. Aerosol Sci. 41: 702-718.

Park, J., Kim, C., Jeong, J., Lee, S.G. and Hwang, J. (2011). Design and evaluation of a unipolar aerosol charger to generate highly charged micron-sized aerosol particles. J. Electrostat. 69: 126-132.

Shin, W.G., Qi, C., Wang, J., Fissan, H. and Pui, D.Y.H. (2009). The effect of dielectric constant of materials on unipolar diffusion charging of nanoparticles. J. Aerosol Sci. 40: 463-468.

Sun, W., Liu, X., Xu, Y., Zhang, Y., Chen, D., Chen, Z. and $\mathrm{Xu}, \mathrm{M}$. (2018). Effects of the modified kaolin sorbents on the reduction of ultrafine particulate matter $\left(\mathrm{PM}_{0.2}\right)$ emissions during pulverized coal combustion. Fuel 215: 153-160.

Wang, C., Liu, X., Li, D., Si, J., Zhao, B. and Xu, M. (2015). Measurement of particulate matter and trace elements from a coal-fired power plant with electrostatic precipitators equipped the low temperature economizer. Proc. Combust. Inst. 35: 2793-2800.

Wang, W., Shao, L., Li, J., Chang, L., Zhang, D., Zhang, C. and Jiang, J. (2019). Characteristics of individual particles emitted from an experimental burning chamber with coal from the lung cancer area of Xuanwei, China. Aerosol Air Qual. Res. 19: 355-363.

Xu, F., Luo, Z., Bo, W., Zhao, L., Gao, X., Fang, M. and Cen, K. (2009). Experimental investigation on charging characteristics and penetration efficiency of $\mathrm{PM}_{2.5}$ emitted from coal combustion enhanced by positive corona pulsed ESP. J. Electrostat. 67: 799-806.

Xu, Y., Liu, X., Cui, J., Chen, D., Xu, M., Pan, S., Zhang, K. and Gao, X. (2016a). Field measurements on the emission and removal of $\mathrm{PM}_{2.5}$ from coal-fired power stations: 4. PM removal performance of wet electrostatic precipitators. Energy Fuels 30: 7465-7473.

Xu, Y., Liu, X., Zhang, Y., Sun, W., Zhou, Z., Xu, M., Pan, S. and Gao, X. (2016b). Field measurements on the emission and removal of $\mathrm{PM}_{2.5}$ from coal-fired power stations: 3. direct comparison on the PM removal efficiency of electrostatic precipitators and fabric filters. Energy Fuels 30: 5930-5936.

Yang, R., Jianmin, Q., Marinis, T. and Wong, C.P. (2000). A precise numerical prediction of effective dielectric constant for polymer-ceramic composite based on effective-medium theory. IEEE Trans. Compon. Packag. Technol. 23: 680-683.

Yang, Z., Zheng, C., Zhang, X., Li, C., Wang, Y., Weng, W. and Gao, X. (2017). Sulfuric acid aerosol formation and collection by corona discharge in a wet electrostatic precipitator. Energy Fuels 31: 8400-8406.

Yang, Z., Zheng, C., Liu, S., Guo, Y., Liang, C., Zhang, X., Zhang, Y. and Gao, X. (2018a). Insights into the role of particle space charge effects in particle precipitation 
processes in electrostatic precipitator. Powder Technol. 339: 606-614.

Yang, Z., Zheng, C., Zhang, X., Chang, Q., Weng, W., Wang, Y. and Gao, X. (2018b). Highly efficient removal of sulfuric acid aerosol by a combined wet electrostatic precipitator. RSC Adv. 8: 59-66.

Yang, Z., Zheng, C., Zhang, X., Zhou, H., Silva, A.A., Liu, C., Snyder, B., Wang, Y. and Gao, X. (2018c). Challenge of $\mathrm{SO}_{3}$ removal by wet electrostatic precipitator under simulated flue gas with high $\mathrm{SO}_{3}$ concentration. Fuel 217: 597-604.

Zheng, C., Chang, Q., Lu, Q., Yang, Z., Gao, X. and Cen, K. (2016). Developments in unipolar charging of airborne particles: Theories, simulations and measurements. Aerosol Air Qual. Res. 16: 3037-3054.

Zheng, C., Wang, Y., Zhang, X., Yang, Z., Liu, S., Guo, Y., Zhang, Y., Wang, Y. and Gao, X. (2018). Current density distribution and optimization of the collection electrodes of a honeycomb wet electrostatic precipitator. RSC Adv. 8: 30701-30711.
Zheng, C., Wang, Y., Liu, Y., Yang, Z., Qu, R., Ye, D., Liang, C., Liu, S. and Gao, X. (2019). Formation, transformation, measurement, and control of $\mathrm{SO}_{3}$ in coal-fired power plants. Fuel 241: 327-346.

Zhou, B., Feng, L., Shiue, A., Hu, S.C., Wang, Y., Li, F., Lin, T., Liu, H.F., Wei, P. and Xu, Y. (2019). Study on influencing mechanism of outdoor plant-related particle on indoor environment and its control measures during transition period in Nanjing. Aerosol Air Qual. Res. 19: 571-586.

Zhuang, Y., Jin Kim, Y., Gyu Lee, T. and Biswas, P. (2000). Experimental and theoretical studies of ultrafine particle behavior in electrostatic precipitators. $J$. Electrostat. 48: 245-260.

Received for review, November 5, 2018

Revised, March 10, 2019 Accepted, March 16, 2019 